\title{
Textile/Polypyrrole Composites for Sensory Applications
}

\author{
Subhankar Maity and Arobindo Chatterjee \\ Department of Textile Technology, Dr. B. R. Ambedkar National Institute of Technology, Jalandhar, Punjab 144011, India \\ Correspondence should be addressed to Subhankar Maity; maity.textile@gmail.com
}

Received 12 June 2015; Revised 7 October 2015; Accepted 8 October 2015

Academic Editor: Federico Juan Sabina

Copyright (C) 2015 S. Maity and A. Chatterjee. This is an open access article distributed under the Creative Commons Attribution License, which permits unrestricted use, distribution, and reproduction in any medium, provided the original work is properly cited.

\begin{abstract}
Electrically conductive woven, knitted, and nonwoven composite fabrics are prepared by in situ chemical polymerization of pyrrole using suitable oxidant and dopant. These composite fabrics show surface resistivity in the range $\sim 1$ to $2 \mathrm{k} \Omega$. These composite fabric can alter their resistivity with various stimuli such as mechanical strain, $\mathrm{pH}$, and humidity. So, in the present study, their response to $\mathrm{pH}$, humidity, and mechanical strain is investigated. For all fabrics, similar behaviour has been observed regarding $\mathrm{pH}$ versus resistivity. The resistance of the composite fabric increases with the increase of alkalinity of $\mathrm{pH}$. However, as bending strain increases, resistance steeply decreases for cotton fabrics, steeply increases for polyester fabrics, and initially decreases and then increases for wool fabrics. Regarding humidity sensitivity, sigmoid curves have been obtained for all kinds of fabrics.
\end{abstract}

\section{Introduction}

Alan MacDiarmid, Alan Heeger, and Hideki Shirakawa have discovered electroconductive polyacetylene and encouraged a new field of research on conductive polymers such as polyaniline, polypyrrole, and polythiophene. These conductive polymers have conductivity above semiconductors and below the metals. Unlike metals, their conductivity can be tailored by varying the level and kinds of doping [1] But they lack processability to form fibres or filaments due to their inherent structural intractability and stiffness that comes from $\pi$ conjugation along molecular chain $[2$, 3]. Among these conductive polymers, polypyrrole (PPy) has low cost, good environmental stability, and satisfactory electrical conductivity in doped condition [4-7]. Textile materials are insulator but strong, light-weight, and flexible. If conductive polymers are applied on the surface of the textile material, then an electroconductive textile composite can be developed, which will be strong, flexible, and light-weight, unlike metals and semiconductors. Electrical conductivity in textile materials can be achieved by metal coating with metal powders or incorporating metal wires into textile structure [8-10]. Metal fibres can be used during spinning process to produce electroconductive yarns [11]. These yarns can be used in weaving or knitting to produce electroconductive fabrics as well. However, manufacturing and postspinning and postweaving operations of these yarns and fabrics are difficult and also they lose textile properties. In this respect, the coating of textile yarns and fabrics by electroconductive polymers may be a useful alternative. Literature says that in situ polymerization methods are very suitable for applications of conductive polypyrrole to textiles [12-17]. These electroconductive textiles are proposed to be used in various applications such as heating pads [3], EMI shielding [16, 17], and sensors $[2,14,15]$. There are few works reported in the literature regarding sensory applications of polypyrrole polymers in pure form or embedded in other structures [1821]. But there is a lack of information about the polypyrrole based composites where various textile structures such as woven, knitted, and nonwovens made of a variety of fibres such as cotton, wool, and polyesters are used as substrate. So the present study aims at the preparation of polypyrrole based textile composites using different fabric made of a variety of fibres and exploration of their characteristics as $\mathrm{pH}$, humidity, and strain sensor.

\section{Materials and Chemicals}

Cotton woven fabric (pain, area weight $150 \mathrm{gm}^{-2}$, ends per inch 56, and picks per inch 56), cotton knitted fabric (single jersey, area weight $150 \mathrm{gm}^{-2}$ ), wool woven fabric (twill $2 / 2$, 
area weight $150 \mathrm{gm}^{-2}$, ends per inch 48 , and picks per inch 43), polyester needle-punched nonwoven fabric (area weight $150 \mathrm{gm}^{-2}$ ), polyester spunlace nonwoven fabric (area weight $100 \mathrm{gm}^{-2}$ ), and polyester plain woven fabric (area weight $150 \mathrm{gm}^{-2}$, ends per inch 56, and picks per inch 56) are used as substrate. Woven fabrics are procured from industry. The needle-punched and spunlace fabrics are manufactured by carding, parallel laying, and mechanical bonding without any chemical additives. Pyrrole (98\% pure, Leonid Chemicals, India) is used as monomer, $\mathrm{FeCl}_{3}$ (Qualigens Fine Chemicals, India) is used as oxidant, and $p$-toluenesulfonic acid (PTSA) monohydrate (SD Fine-chemicals Ltd., India) is used as dopant. All these chemicals are of laboratory grade and are used as received.

\section{Experimental Methods}

All fabric samples are scoured before use. Scouring of cotton fabrics is done in a solution of $4 \%$ caustic soda $(\mathrm{NaOH})$ and $2 \%$ sodium carbonate $\left(\mathrm{Na}_{2} \mathrm{CO}_{3}\right)$ at $130^{\circ} \mathrm{C}$ for 4 hours. Material to liquor ratio is kept at $1: 20$. Scouring of wool fabric is carried out in a solution of $3 \%$ detergents (oleate soap) and $2 \%$ sodium carbonate at $50^{\circ} \mathrm{C}$ for $15 \mathrm{~min}$. Material to liquor ratio is kept at $1: 20$. Scouring of polyester fabrics is carried out in an alkaline solution of $2 \mathrm{gL}^{-1}$ caustic soda, $1 \mathrm{gL}^{-1}$ soda-ash, and $1 \mathrm{gL}^{-1}$ Lissapol $\mathrm{N}$ with a treatment time of $60 \mathrm{~min}$ at a temperature of $80^{\circ} \mathrm{C}$. The material to liquor ratio is kept at 1:20 for all cases. Polyester fabric samples are hydrolyzed after scouring, with $10 \%$ sodium hydroxide for 20 minutes at boil keeping material to liquor ratio at 1:40. After scouring/hydrolysis, all the fabric samples are neutralised with $0.1(\mathrm{~N})$ acetic acid solutions and rinsed thoroughly with water. Then, an in situ chemical polymerization method is followed for preparation of polypyrrole/textile composites as shown in Figure 1. Monomer and oxidant solution are prepared in a separate bath. Monomer bath of $0.5 \mathrm{M}$ concentration is prepared by dissolving pyrrole in deionized water. Material to liquor ratio of monomer bath is $1: 20$. Oxidant bath is prepared by dissolving $\mathrm{FeCl}_{3}$ and PTSA in deionized water. The amount of $\mathrm{FeCl}_{3}$ and PTSA used is $0.25 \mathrm{M}$ and $0.05 \mathrm{M}$, respectively. Material to liquor ratio is $1: 20$. Then both monomer and oxidant solutions are cooled down to $5^{\circ} \mathrm{C}$ in a cryostat instrument. After cooling both solutions are poured and mixed in a separate beaker where textile fabric is kept. As a result in situ polymerization of pyrrole starts leading to deposition of polypyrrole on the fabric surface. This beaker of polymerization is kept in a cryostat at $5^{\circ} \mathrm{C}$ for 60 minutes and frequently stirred with a glass rod. After the polymerization, samples are taken out from polymerization bath, thoroughly rinsed with cold water, and dried in an oven at $80^{\circ} \mathrm{C}$ for 3 hours. After that samples are conditioned at $22 \pm 2^{\circ} \mathrm{C}$ temperature and $65 \pm 5 \%$ relative humidity for 48 hours before the measurement of surface resistivity.

\section{Measurement Methods}

Polymer add-on percentages of electroconductive fabric samples are calculated by taking oven dry weight of samples

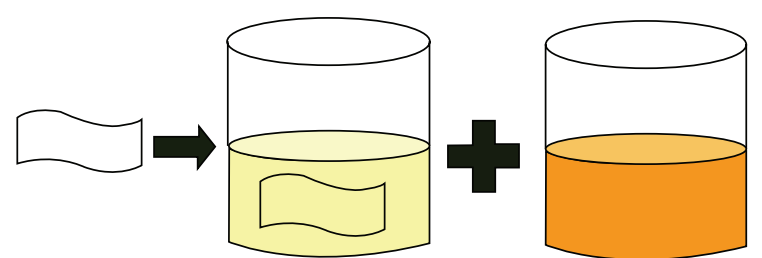

Sample dipped in pyrrole solution $\mathrm{FeCl}_{3}$ solution

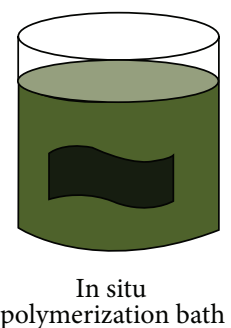

polymerization bath

FIGURE 1: In situ chemical polymerization of pyrrole onto textile fabrics.

before and after in situ polymerization. The polymer add-on percentage is the difference between the final weight and the initial weight of the fabric expressed as a percentage of the initial weight. The surface resistivity of polypyrrole coated fabrics is measured by the concentric ring electrode probe method as per AATCC Test Standard 76-2005 at $22 \pm 2^{\circ} \mathrm{C}$ temperature and $65 \%$ relative humidity. A digital multimeter (MASTEC MAS830L) is used for taking the measurement in conjunction with concentric ring electrode probe.

\section{Results and Discussions}

5.1. Surface Resistivity of Electroconductive Composite Fabric. The surface resistivity and polypyrrole add-on all of the electroconductive fabrics are measured and the average surface resistivity of 20 observations is shown in Table 1 . It can be seen that lowest resistivity and highest add-on achieved in the case of polyester needle-punched nonwoven fabric due to its thicker, bulkier, and porous structure. If we compare fibres, then wool fibres show better add-on and lower resistivity than those of the polyester and cotton. This may be due to the irregular/scaly wool surface and higher chemical interaction between wool and polypyrrole.

5.2. SEM Analysis of Polypyrrole Coated Textile Fabrics. SEM images of the untreated and PPy coated fabrics are shown in Figure 2. It has been seen that all individual fibres are coated with polypyrrole polymer quite uniformly. Granular morphology of PPy is observed on the fibre surface. A significant amount of polypyrrole is also present in fibre interstices. This finding confirms that the polymerization proceeded smoothly resulting in the formation of a uniform layer of PPy around the individual fibres as well as in the fibre interstices.

5.3. Effect of $p H$ of Surface Resistivity of Electroconductive Composite Fabric. Change of electrical resistance of all 
TABLE 1: Surface resistivity and polypyrrole add-on of polypyrrole coated fabrics.

\begin{tabular}{lcccccc}
\hline $\begin{array}{l}\text { Polypyrrole coated } \\
\text { fabrics }\end{array}$ & $\begin{array}{c}\text { Cotton } \\
\text { woven fabric }\end{array}$ & $\begin{array}{c}\text { Cotton } \\
\text { knitted fabric }\end{array}$ & $\begin{array}{c}\text { Wool woven } \\
\text { fabric }\end{array}$ & $\begin{array}{c}\text { Polyester } \\
\text { woven fabric }\end{array}$ & $\begin{array}{c}\text { Polyester } \\
\text { needle-punched } \\
\text { nonwoven }\end{array}$ & $\begin{array}{c}\text { Polyester spunlace } \\
\text { nonwoven }\end{array}$ \\
\hline $\begin{array}{l}\text { Average surface } \\
\text { resistivity }[\Omega]\end{array}$ & 1357 & 1223 & 1137 & 1234 & 1013 & 1099 \\
$\begin{array}{l}\text { Standard deviation of } \\
\text { resistivity }[\Omega]\end{array}$ & 119.80 & 106.22 & 111.12 & 38.60 & 25.44 & 75.88 \\
\begin{tabular}{l} 
Polypyrrole add-on $[\%]$ \\
\hline
\end{tabular} & 15.4 & 16.3 & 18.12 & 14.4 & 29.35 & 20.2 \\
\hline
\end{tabular}
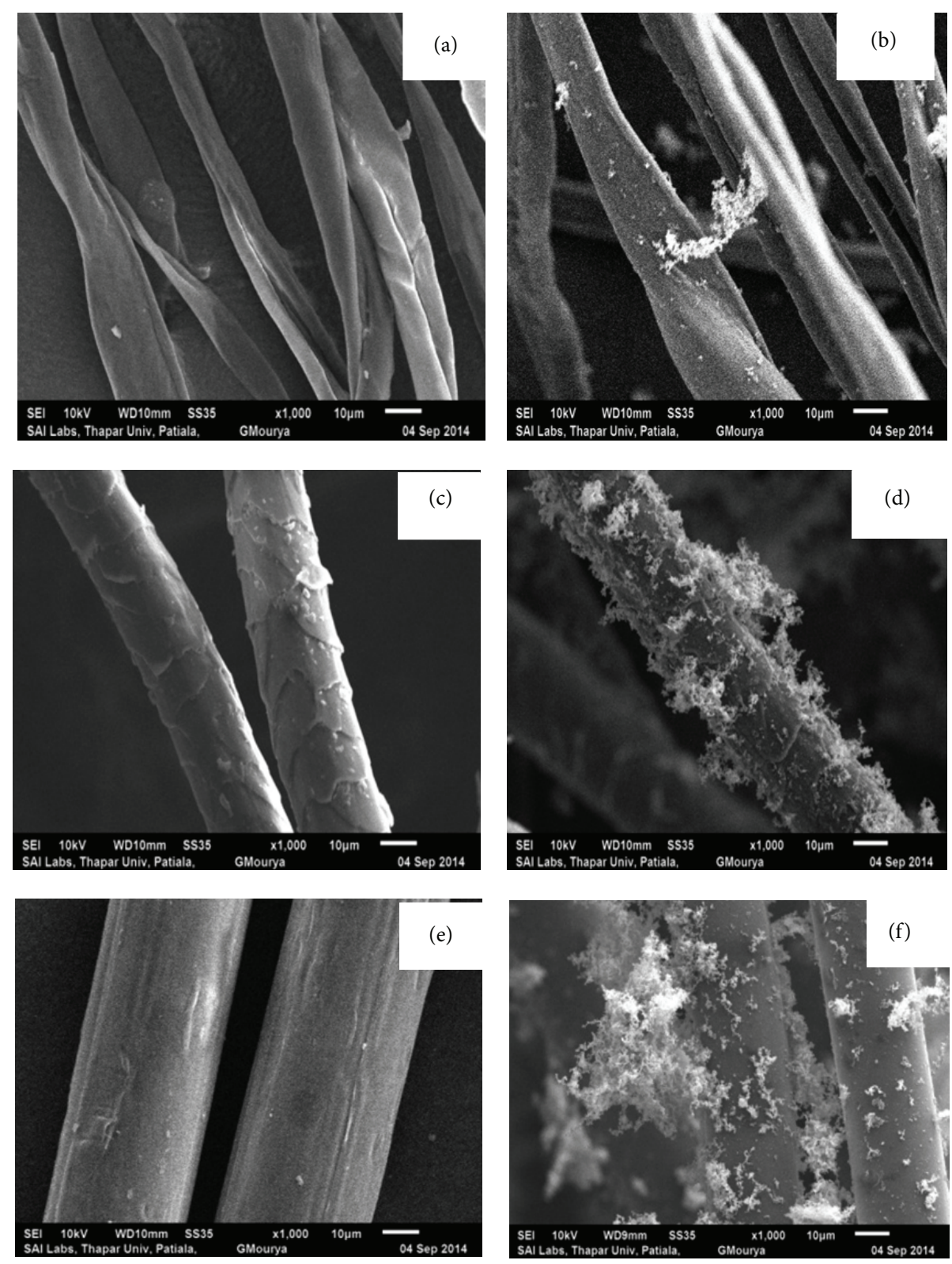

FIGURE 2: SEM images of (a) untreated cotton, (b) PPy coated cotton, (c) untreated wool, (d) PPy coated wool, (e) untreated polyester, and (f) PPy coated polyester. 
TABLE 2: Effect of $\mathrm{pH}$ on resistance of polypyrrole coated fabrics.

\begin{tabular}{lcccccc}
\hline \multicolumn{6}{c}{ Fractional change of resistance of fabrics $=($ Final resistance - Initial resitance)/Initial resistance $=\Delta R / R$} \\
$\mathrm{pH}$ & Cotton woven & Cotton knitted & Wool woven & Polyester woven & Polyester spunlace & Polyester needle-punched \\
\hline 2 & -0.59 & -0.53 & -0.49 & -0.15 & -0.209 & -0.309 \\
3 & -0.43 & -0.43 & -0.46 & -0.13 & -0.053 & -0.153 \\
4 & -0.40 & -0.23 & 0.01 & -0.12 & 0.010 & 0.101 \\
5 & -0.37 & -0.07 & 0.09 & 0.10 & 0.023 & 0.123 \\
6 & -0.11 & -0.01 & 0.31 & 0.14 & 0.160 & 1.160 \\
7 & 0.05 & 0.05 & 0.41 & 0.18 & 0.527 & 1.527 \\
8 & 0.10 & 0.10 & 0.59 & 0.20 & 0.820 & 1.160 \\
9 & 0.30 & 0.03 & 1.14 & 0.23 & 1.760 & 2.160 \\
10 & 0.60 & 0.52 & 1.38 & 0.25 & 2.180 & 3.760 \\
11 & 2.79 & 2.90 & 2.28 & 0.36 & 7.362 & 8.180 \\
12 & 11.4 & 10.4 & 6.00 & 3.60 &
\end{tabular}

electroconductive composite fabrics is measured by dipping the fabric samples of specific dimension in different $\mathrm{pH}$ solution and connecting with a digital multimeter. $\mathrm{pH}$ solutions of all ranges from 2 to 13 are prepared by dissolving acetic acid and caustic soda in deionized water for acidic and alkaline $\mathrm{pH}$, respectively. Small samples of dimension of $2.54 \mathrm{~cm} \times 2 \mathrm{~cm}$ are prepared for all types of composite fabrics and fixed on a glass strip of the same dimension with the help of metallic clips attaching both ends in lengthwise. The clips are connected with a digital multimeter to measure the initial resistance of the composite fabric. Then strip assembly is immersed in a particular $\mathrm{pH}$ solution and change in resistance is observed. This measurement is done for all kinds of fabric samples by taking a fresh strip of fabric for each $\mathrm{pH}$ solution. The fractional change of electrical resistance, that is, the $\mathrm{pH}$ sensitivity of all kind of fabrics for the different $\mathrm{pH}$ solution, is given in Table 2. Figure 3 shows the characteristic curves of $\mathrm{pH}$ sensitivity for all kinds of composite fabric. It can be seen that all kinds of fabrics follow a similar characteristic curve and as basicity of the solution increases resistivity increases. However, after a certain level of basic $\mathrm{pH}$ the resistivity of the fabrics increases drastically. An increase in the solution $\mathrm{pH}$ caused a decrease of the doping level due to the release of part of the counter-ions leading to an increase in the surface resistivity. A similar observation is earlier made by Molina et al. [18].

5.4. Effect of Bending Strain on Resistivity of Conductive Fabrics. Fabric samples are cut in strips of $10 \mathrm{~cm} \times 2 \mathrm{~cm}$ dimension for testing. Each fabric strip is fixed on an insulating flexible plastic strip of the same dimension. The ends of the sample are connected with a multimeter by metal clips and wire for measuring the resistance. The plastic strip with the sample is bending with different bending angle $(\theta)$ as shown in Figure 4 and corresponding resistance of the sample is measured by the multimeter. The results have been shown in Figure 5. It can be seen from Figure 5 that as bending angle, that is, strain in the samples, increases electrical resistivity of all fabrics changes. The electrical resistivity monotonously decreases in the case of cotton composites, initially decreases and then increases in case of

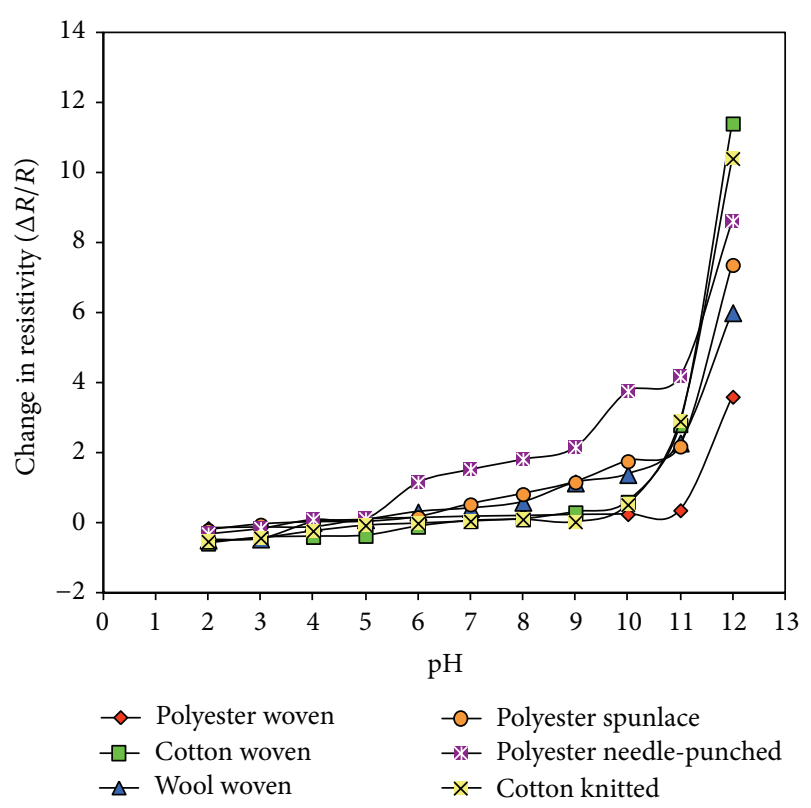

Figure 3: Effect of $\mathrm{pH}$ on resistance of polypyrrole coated fabrics.

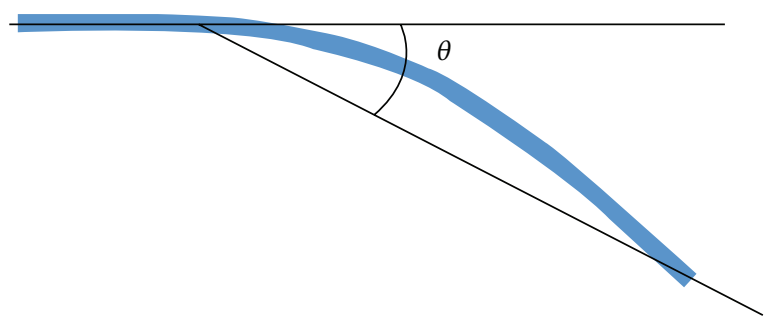

FIGURE 4: Bending angle.

wool composites, and monotonously increases in case of all polyester composites. The increase or decrease of electrical resistivity is due to the redistribution of contact points of flow of charge through the structure upon bending. In case of cotton fabric, the redistribution of contact points is in favour of decrease of the fabric resistance and, for other fabrics, 


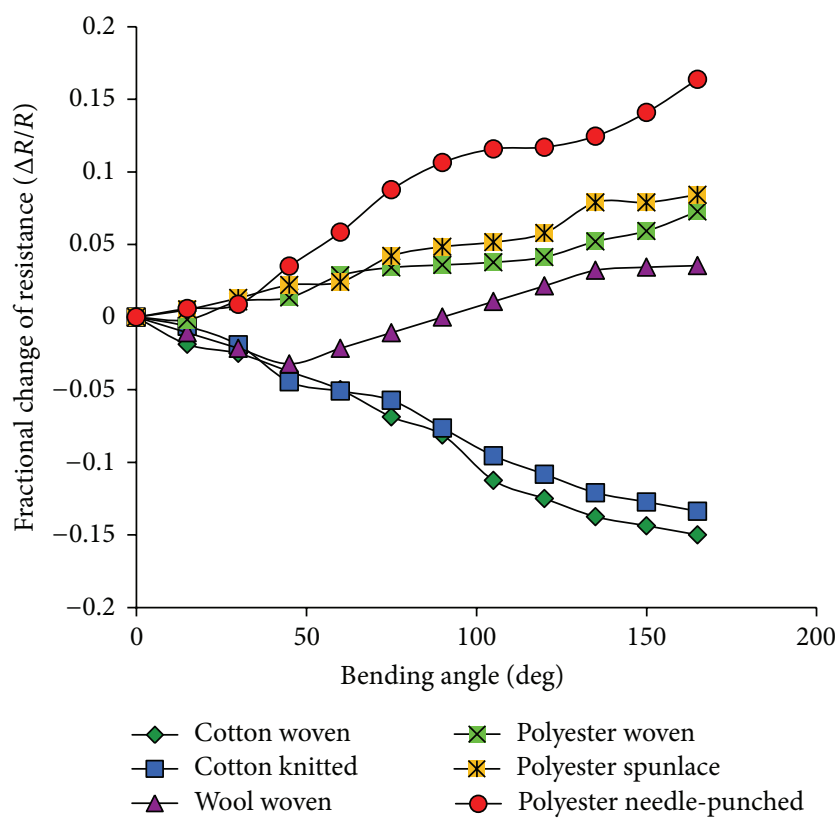

Figure 5: Effect of bending on resistance of electroconductive composite fabrics.

it is in favour of increase of resistance. It is understood that there are various factors that may affect this redistribution of contact points, such as fibre-polymer interaction, functional groups in the fibre, number of fibres in the equivalent weight of fabric, shape of the fibre, twist in the fibre, and fabric structure. Here, four different fabrics made of three different fibres are used in this study and the fibres are having different density, shape, and functional groups. All these factors may influence the redistribution of contact points. For understanding the reason or factors that influence the redistribution of contact points in favour of increase or decrease of resistance, a further investigation is required.

5.5. Effect of Humidity on Resistance of Electroconductive Composite Fabrics. Here, samples of size $(10 \times 10) \mathrm{cm}$ are taken from all types of composite fabrics for further analysis. All fabric samples are firstly oven dried and their oven dry weight and surface resistivity at oven dry condition are measured by concentric ring probe electrode. Then fabric samples are wetted properly by dipping them in deionized water and again weight and surface resistivity are measured. Then, these fully wet samples are kept in an oven drier for few minutes for partial drying and taken out for measurement of weight and corresponding surface resistivity. In this way, few measurements are carried out during their drying period before the fabrics are fully dried. The moisture content of the samples is calculated at every stage of drying and corresponding surface resistivity is noted down for analysis. The results obtained by these experiments are shown in Figure 6. It can be seen from Figure 6 that as the moisture content of the composite fabric increases, surface resistivity decreases and sigmoid curves have been obtained for all kinds of composite fabric. Initially, decrement rate of resistance is higher with

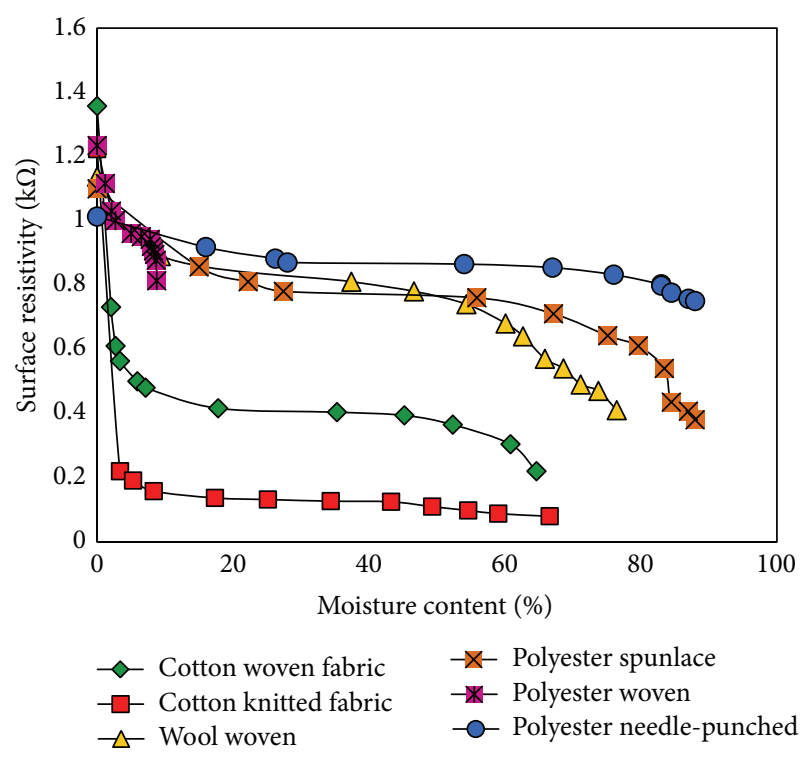

FIGURE 6: Effect of moisture sensitivity of polypyrrole coated composite fabrics.

the increase of moisture content up to a certain level and afterwards the curves flatten. However, after achieving certain levels of moisture content in the fabrics, a higher rate of decrement of resistivity has been observed again for all kinds of composite fabric. The initial drop of resistivity is found higher in case of cotton fabrics, because, upon water uptake, ion mobility of PPy increases and moreover individual cotton fibres swell upon water uptake and establish better polymer contacts in fibre interstices to reduce the resistivity. Also, the interaction between the fibre and water molecule may play a significant role in contributing electrical conductivity. For this reason, being a hydrophilic fibre, cotton shows a higher rate of drop in resistivity upon moisture uptake, whereas the wool surface is hydrophobic due to the dry scales on its surface, lacking fibre-water interactions. But it can absorb moisture through the pores of scales and swell which enhances ion mobility of PPy as well as establishing better polymer contacts in fibre interstices to reduce resistivity. In case of polyester fabrics, polyester fibres do not swell, but the PPy inside polyester fabrics enhances ion mobility upon water uptake and as a result resistance reduces.

\section{Conclusions}

Polypyrrole coated textile composite fabric have been successfully prepared by in situ chemical polymerization of pyrrole onto textile fabrics using ferric chloride as oxidant and $p$-toluenesulfonic acid as a dopant. Cotton, wool, and polyester fibres can be successfully coated in this way with polypyrrole. Polypyrrole coated textile composite fabrics can change their resistance substantially by changing environmental $\mathrm{pH}$ and environmental humidity and by applying strain. The resistance of the composite fabric increases with the increase of alkaline $\mathrm{pH}$. As strain increases in the composite structure, resistance steeply decreases for cotton 
fabrics, steeply increases for polyester fabrics, and initially decreases and then increases for wool fabrics. Regarding humidity sensitivity, sigmoid curves have been obtained for all kinds of fabrics.

\section{Conflict of Interests}

The authors declare that there is no conflict of interests regarding the publication of this paper.

\section{References}

[1] A. K. Bakhshi and G. Bhalla, "Electrically conducting polymers: materials of the twentyfirst century," Journal of Scientific and Industrial Research, vol. 63, no. 9, pp. 715-728, 2004.

[2] S. Maity and A. Chatterjee, "Preparation and characterization of electro-conductive rotor yarn by in situ chemical polymerization of pyrrole," Fibers and Polymers, vol. 14, no. 8, pp. 14071413, 2013.

[3] S. Maity, A. Chatterjee, B. Singh, and A. P. Singh, "Polypyrrole based electro-conductive textiles for heat generation," Journal of the Textile Institute, vol. 105, no. 8, pp. 887-893, 2014.

[4] B. Kim, V. Koncar, and E. Devaux, "Electrical properties of conductive polymers: pet-nanocomposites' fibres," Autex Research Journal, vol. 4, no. 1, pp. 9-13, 2004.

[5] R. M. McConnell, W. E. Godwin, S. E. Baker, K. Powell, M. Baskett, and A. Morara, "Polyfuran and co-polymers: a chemical synthesis," International Journal of Polymeric Materials and Polymeric Biomaterials, vol. 53, no. 8, pp. 697-708, 2004.

[6] C. Della Pina, E. Falletta, and M. Rossi, "Conductive materials by metal catalyzed polymerization," Catalysis Today, vol. 160, no. 1, pp. 11-27, 2011.

[7] M. Omastová and M. Mičušík, "Polypyrrole coating of inorganic and organic materials by chemical oxidative polymerisation," Chemical Papers, vol. 66, no. 5, pp. 392-414, 2012.

[8] A. Bhattacharya and A. De, "Conducting composites of polypyrrole and polyaniline a review," Progress in Solid State Chemistry, vol. 24, no. 3, pp. 141-181, 1996.

[9] G. Plantard and M. Papini-Arconada, "Analysis of the radiative properties of insulating and conducting granular polymers and of their mixtures," Powder Technology, vol. 128, no. 2-3, pp. 287295,2002

[10] A. Kaynak and R. Foitzik, "Methods of coating textiles with soluble conducting polymers," Research Journal of Textile and Apparel, vol. 15, no. 2, pp. 107-113, 2011.

[11] D. Kincal, A. Kumar, A. D. Child, and J. R. Reynolds, "Conductivity switching in polypyrrole-coated textile fabrics as gas sensors," Synthetic Metals, vol. 92, no. 1, pp. 53-56, 1998.

[12] P. A. Mabrouk, "Oxidative electropolymerization of pyrrole from neat monomer solution," Synthetic Metals, vol. 150, no. 1, pp. 101-105, 2005.

[13] F. Ferrero, L. Napoli, C. Tonin, and A. Varesano, "Pyrrole chemical polymerization on textiles: kinetics and operating conditions," Journal of Applied Polymer Science, vol. 102, no. 5, pp. 4121-4126, 2006.

[14] U. Malhotra, S. Maity, and A. Chatterjee, "Polypyrrole-silk electro-conductive composite fabric by in situ chemical polymerization," Journal of Applied Polymer Science, vol. 132, no. 4, Article ID 41336, 2015.
[15] S. Maity and A. Chatterjee, "Polypyrrole based electroconductive cotton yarn," Journal of Textile Science and Engineering, vol. 4, no. 6, article 171, 2014.

[16] S. Maity and A. Chatterjee, "Non-metallic electro-conductive textiles based on conductive polymers," Asian Textile Journal, vol. 24, no. 5, pp. 57-62, 2015.

[17] S. Maity and A. Chatterjee, "Conductive polymer based electroconductive textiles for novel applications," Technical Textiles, vol. 1, pp. E16-E18, 2015.

[18] J. Molina, J. Fernández, A. I. del Río, R. Lapuente, J. Bonastre, and F. Cases, "Stability of conducting polyester/polypyrrole fabrics in different $\mathrm{pH}$ solutions. Chemical and electrochemical characterization," Polymer Degradation and Stability, vol. 95, no. 12, pp. 2574-2583, 2010.

[19] C. Mattmann, F. Clemens, and G. Tröster, "Sensor for measuring strain in textile," Sensors, vol. 8, no. 6, pp. 3719-3732, 2008.

[20] S. Rajagopalan, M. Sawan, E. Ghafar-Zadeh, O. Savadogo, and V. P. Chodavarapu, "A polypyrrole-based strain sensor dedicated to measure bladder volume in patients with urinary dysfunction," Sensors, vol. 8, no. 8, pp. 5081-5095, 2008.

[21] B. Adhikari and S. Majumdar, "Polymers in sensor applications," Progress in Polymer Science, vol. 29, no. 7, pp. 699-766, 2004. 

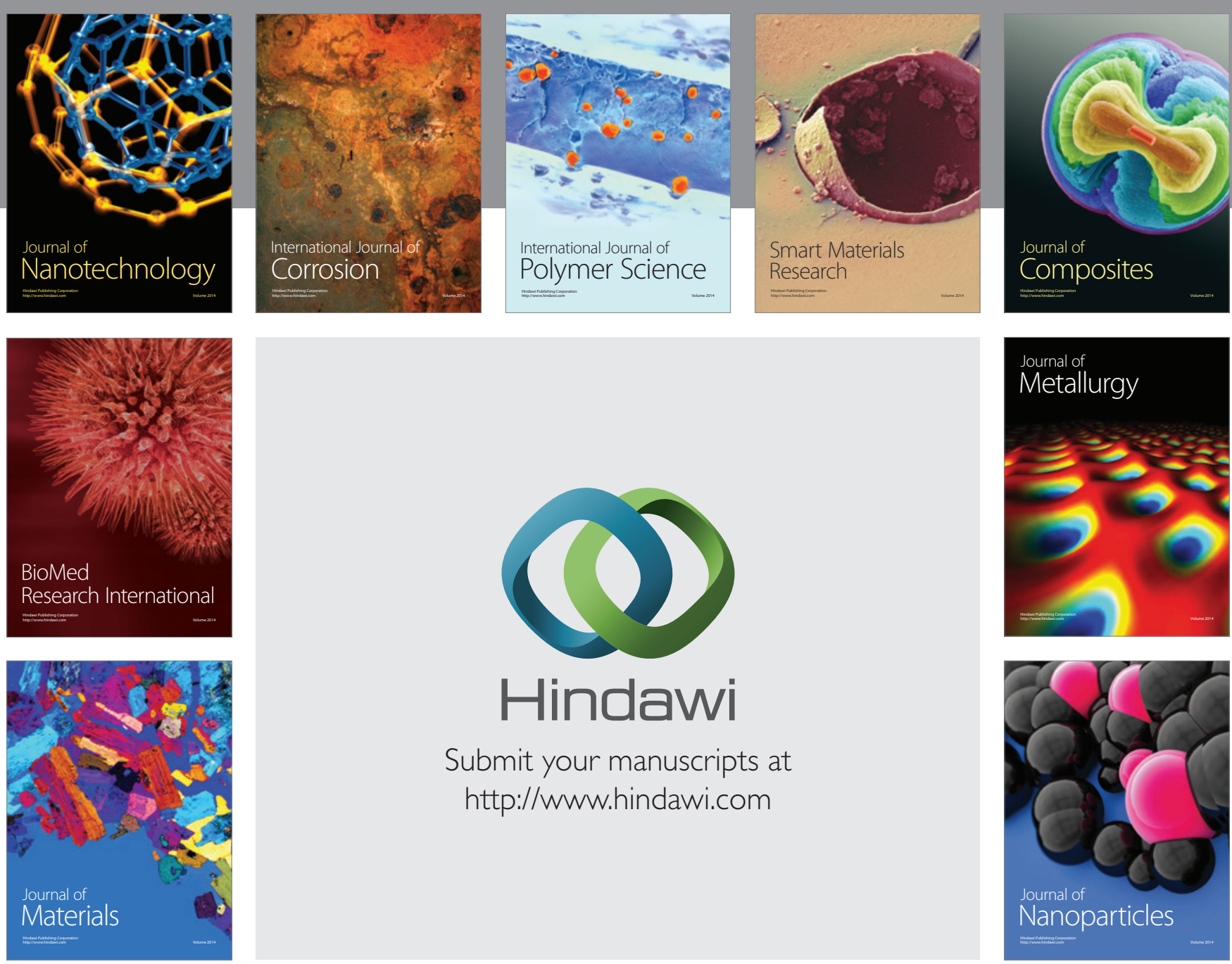

Submit your manuscripts at http://www.hindawi.com
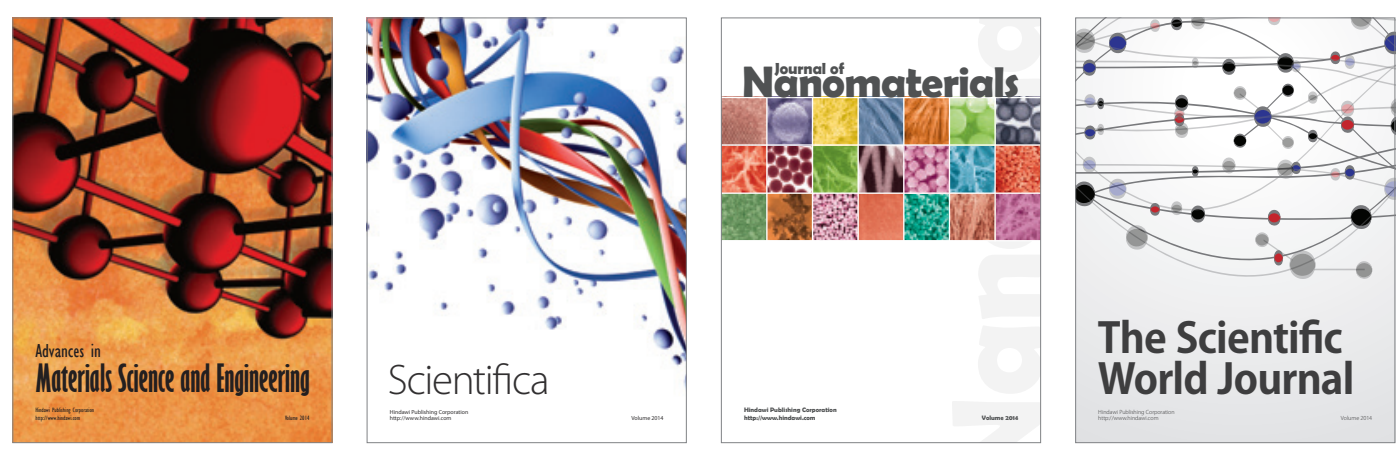

\section{The Scientific World Journal}
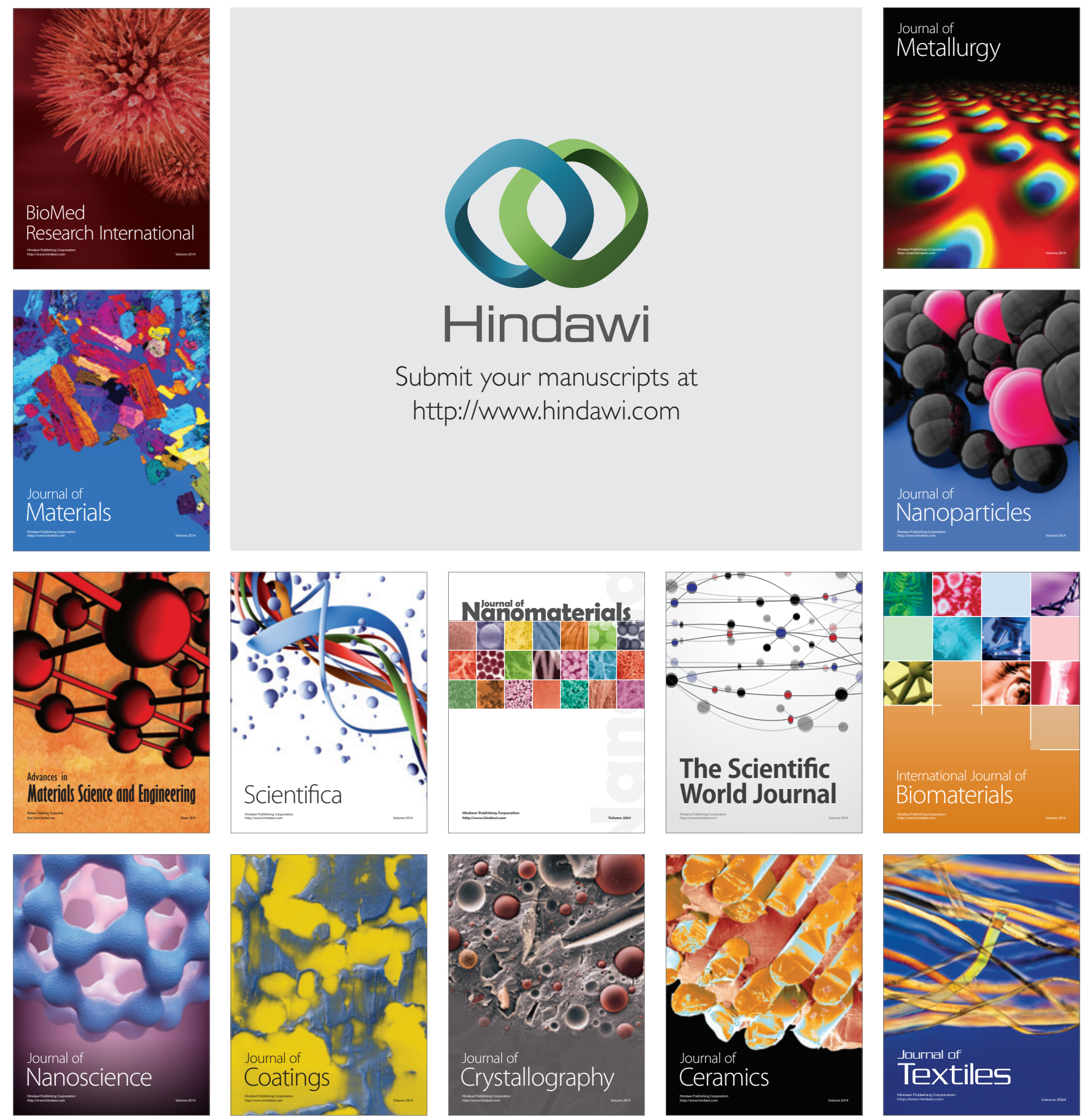